Yuliia BOIKO$^{1}$, Iryna HARKO², Ruslana ZIUBINA ${ }^{3}$, Valerii KOZLOVSKYI ${ }^{4}$

DOI: https://doi.org/10.53052/9788366249868.01

\title{
ANALIZA METOD OKREŚLANIA PREFERENCJI EKSPERTÓW
}

Streszczenie: Systemy wspomagania decyzji są wygodnym narzędziem wspierającym działania eksperta. W niniejszej pracy przeanalizowano najbardziej powszechne metody określania preferencji w celu wybrania najlepszych metod projektowania system wspomagania decyzji. Przeprowadzono klasyfikację metod określania współczynników ważności i zbadano możliwość ich wykorzystania do projektowania system wspomagania decyzji.

Słowa kluczowe: SWD, metody porównań parami, ranking kryteriów, metody porządkowego skalowania, metoda wskaźnikowo - punktowa

\section{ANALYSIS OF METHODS FOR DETERMINING THE EXPERTS' PREFERENCES}

Summary: The paper is devoted to the study of the most common methods of determining preferences, in order to select the best methods for DSS design. The classification of methods for determining the coefficients of importance is obtained. And the possibility of their use for designing a software system for decision support was investigated.

Keywords: DSS, pairwise comparison method, criteria ranking method, ordinal scaling methods, evaluation methods on the scale of relations.

\section{Introduction}

Intensive development of computer and telecommunication technologies opens fundamentally new opportunities for construction and development of automated information systems to solve management problems. Solving the problems of timely optimal decision-making was impossible without the development and use of

\footnotetext{
${ }^{1}$ Kijowski Uniwersytet Narodowy im. Tarasa Szewczenki: Katedra Stosowanych Systemów Informatycznych: julia_boyko2010@ukr.net

${ }^{2}$ Kijowski Uniwersytet Narodowy im. Tarasa Szewczenki: Katedra Stosowanych Systemów Informatycznych: Department of Applied Information Systems: garko.iryna@gmail.com

${ }^{3}$ Akademia Techniczno-Humanistyczna w Bielsku-Białej, Katedra Informatyki i Automatyki: rziubina@ath.bielsko.pl

${ }^{4}$ Narodowy Uniwersytet Lotniczy, Katedra Bezpieczeństwa Informacji: kzzi@nau.edu.ua
} 
effective software that supports the activities of the decision-maker. Therefore, decision support systems (DSS) have become widespread.

The market offers a wide range of decision support software. DSS analysis $[1,2]$ showed that most of these systems are based on the analytic hierarchy process. However, there are many methods by which you can determine the experts' judgment preferences, which differ in the type of source information about the advantages and ways to process it. Therefore, it is important to study the most common methods of determining the preferences, in order to select the best methods for designing DSS. The purpose of this paper is to study the methods of determining the experts' preferences and the possibility of their use for DSS design.

\section{The main part}

In many decision-making tasks, the choice of strategies is made through evaluation using several criteria [3]. This class of problems is called multicriteria. However, there is a problem of their assessment and correct processing of these assessments. The problem of determining the preferred criteria does not lose its relevance, many wellknown scientists are engaged in the study of this issue. At the same time, the number of publications with various classifications and comparative analysis of these methods is not very large. There are several works with the most extended classifications [4, 5], which are relatively old, but have not lost their relevance.

Based on the analysis, we will identify a set of methods that are most suitable for processing the expert's judgments and are suitable for building a software system to support decision-making. We organize the methods according to the following features: methods of determining priority; methods for determining weight vectors; scale assessment methods; methods of constructing a generalized criterion.

\subsection{Methods of determining priority.}

The methods of determining the priority include the following methods: the Delphi method, the pairwise comparison method, the multiple comparison method, the ranking method, the method of criteria normalization, the method of convolution criteria, the method of cluster analysis. Let's take a closer look at these methods.

The Delphi method has an algorithm that consists of the following stages $[4,6]$ : determining the value of the predicted value and calculating the variance of estimates, which determines the distribution of the expert's judgments $(N)$; finding the standard deviation of the forecast and the coefficient of variation that characterizes the single expert's judgment; from the obtained data is estimating the range of the predicted value, in which it is contained with a given probability $p$.

In the pairwise comparison method, objects are compared in pairs by one or more experts. The main experts' task is to compare two objects $A$ and $B$ and choose one of them. The pairwise comparisons method is used when comparative objects can be compared subjectively, ie when it is impossible or unprofitable to give an appropriate value to decide which of the two objects is preferable [7].

The multiple comparison method is similar to the method of pairwise comparisons, but differs in that the objects are not compared in pairs with each other, but each relative to each other. For example, if three objects $A, B, C$ are compared in pairs, 
then comparisons $(A B),(A C),(B C)$ are used. The result of comparison can be: $A \rightarrow$ $B, A \rightarrow C, B \rightarrow C$, where " $\rightarrow$ " means "has a greater advantage over". It is also convenient to present the result as an array of numbers [2 10 ], which means that one object "wins" twice, the second - once, and the third - none. The Condorcet method and Borda count method are representatives of this class [8].

In the ranking method, experts have a certain number of ranking objects and must arrange them in a certain order (ascending or descending), according to their advantages. Ranking is used in cases where direct assessment is impossible or impractical. Numbers from 1 to $n$ denotes ranks, where $n$ is the number of ranks. The process of ranking alternatives by experts consists of the following stages: each expert makes judgments about the ranks of objects; for each object it is necessary to calculate the sum of ranks received from all experts; rank the objects from the lowest to the highest result rank [9].

The method of criteria normalization can be applied in the case when the local criteria have different units of measurement. In this case, the criteria must be normalized. The most common way to normalize is to replace the absolute values of the criteria with relative ones.

In methods based on the convolution of criteria, from local criteria must be formed one. The most common is the method of linear combination of partial criteria. Suppose that $a=\left(a_{1}, a_{2}, \ldots, a_{k}\right)$ is a vector of weight coefficients of the criteria characterizing the importance of the corresponding criterion. The linear scalarized function is the sum of partial criteria multiplied by weighting factors.

The method of cluster analysis is to divide the data into groups of similar objects. Each group (cluster) consists of objects that are similar to each other, but different from the objects of other groups [10].

\subsection{Methods for determining weight vectors.}

This group of methods includes methods for determining the priority vector and methods for determining the eigenvectors of weighting factors.

The group of methods for determining the priority vector includes the following methods: Fedulov's method and Mashunin's method [4].

The group of methods for determining the eigenvectors of weights includes: the methods of least squares, methods of analysis the matrices of pairwise comparisons and ranking criteria methods. The methods of analysis the matrices of pairwise comparisons include the methods of least squares and methods of eigenvectors (Wey's method, Saati method, Yushmanov's method, Cogger and Yu's method, von Neumann-Morgenstern method) [5, 7].

Methods of least squares. In this group of methods, the weighting factors are determined from the solution of similar optimization models. Various optimization models use the iterative Marquardt algorithm to obtain weighting factors. A modified Marquardt algorithm, also called the Levenberg-Marquardt algorithm, is used to solve nonlinear problems by the method of least squares [4].

The Wey's method is based on the analysis of a matrix of pairwise comparisons, in which the coordinates of the eigenvector are determined for each alternative by adding elements in each of the rows of the matrix. We will have numerical characteristics of the importance of the criteria, and if we divide them by the total amount, we will obtain the weighting factors of the criteria [11]. 
The Saati method is a modification of the Wey's method, and assumes that the sum of the relative weight vectors of these criteria is 1 . To find the weight vector, it is necessary to solve the inequality. Since the rank of the matrix is equal to 1 , then $n$ is the only eigenvalue of this matrix, ie this inequality has zero value. Moreover, it has the only solution that has the property $\sum_{i=1}^{n} \lambda_{i}=1$. This solution is the vector of relative weights of the criterion - the Saati vector [12].

Yushmanov's method is based on the algorithm for constructing an "island" tree in a weighted complete graph by finding the correct numbering and choosing the optimal set $A_{n}$ [4]. Algorithm for finding the correct numbering. Assign the number $n$ at random to the selected vertex. If you have already marked $k$ vertices with numbers from $n$ to $n-k+1$, then select the unmarked vertex adjacent to the already marked one and assign it the number $n-k$ [13]. Algorithm for choosing the optimal set $A_{n}$. First, we choose a pair with $j(j>i)$, in which the relation $a_{i j}=\frac{\lambda_{i}}{\lambda_{j}}$ is the easiest to estimate, find it and construct a graph $G\left(A_{n}\right)$, consisting of one edge $(i j)$. At each subsequent step, among all pairs $(i j)$ such that one of the vertices lies in $G\left(A_{n}\right)$ and the other does not, we choose the pair for which the relation $a_{i j}$ is easiest to estimate, evaluate it and add an edge $(i j)$ to $G\left(A_{n}\right)$ [13].

The von Neumann-Morgenstern method is based on the assumption that the expert can indicate the probability $p(0 \leq p \leq 1)$ for any alternative $a_{i}$ better than $a_{j}$. The essence of the mixed alternative is that the alternative $a_{i}$ is chosen with probability $p$, and the alternative $a_{j}$ - with probability $(1-p)$. Obviously, if $p$ is close enough to 1 , then alternative $a_{j}$ is less preferable than mixed alternative $\left[p a_{i},(1-p) a_{i}\right]$; if $p$ is close enough to 0 , then the alternative $a_{j}$ is better than the mixed alternative $\left[p a_{i},(1-p) a_{i}\right][14]$.

The ranking methods include: the method of approximation of the monotonic function, the Churchman-Ackoff method, the Podynovsky's method, the Tintarev\&Trofimov method, the Gmoshinsky's method, the sequential comparison method [15].

The method of approximation of a monotonic function is based on various rank transformations or their replacement by the values of a monotonically decreasing function of an integer argument [16].

The Churchman-Ackoff method. As a result of pairwise comparisons of the sums of the criteria, a system of inequalities is obtained, which defines a polygon, any point inside which can be taken to obtain weighting factors. Suzuki proposes to use the center of the polygon to obtain the weights of the coefficients, Bradley and Shubik propose to build a hyperplane that passes through the maximum number of vertices of the polygon and to determine the weights take any point on this hyperplane [17].

The Podynovsky's method. This method uses the idea of optimization according to a given scalar quality criterion on solutions determined from the condition of optimization of the second scalar quality indicator $[8,18]$.

The Tintarev\&Trofimov method. If the problem considers quantitative or ranking scales, then as a result of solving the DSS problem when using additive convolution should be obtained taking into account the value for each alternative [19].

The Gmoshinsky's method is a method of obtaining the weight of each criterion by alternatives from a group of experts after receiving the results of the examination. Firstly, this approach allows you to more accurately determine the importance of each 
criterion, even if there are too many. Secondly, it is considered that the importance of the criterion is constant and independent of the expert, as well as of the problem situation for which the conditions are assessed. From the point of view of the author of the method, a way is proposed to find the distances from the trajectories of alternatives for each criterion to construct an ideal trajectory determined by the last method of finding the common. [4].

The sequential comparison method is that the expert is given a list of factors (criteria, alternatives, results) that need to be assessed by their relative importance (significance), and he ranks them. The most important factor is given a weight $v_{i}$ equal to one, and other factors of evaluation between zero and one in ascending order of their relative importance. The expert then determines whether a factor with a score of 1 is more important than a combination of other factors [20].

\subsection{Scale assessment methods.}

Another type of assessment is widely used by experts - scale assessment. This class of methods can be divided into: ordinal scaling methods, which are also known as scoring methods, and evaluation methods on the scale of relations. The scoring methods include: the interval estimating method and the Coombs "ordered metrics" method [21].

The interval estimating method offers the construction of the ranking result according to the estimates of experts, given in the form of an interval of values of indicators. Suppose a given set $A_{i}=\left\{x_{1}, \ldots, x_{M}\right\}$ consisting of $M$ variants presented by a commission of $N$ experts. The evaluation of each variant $x_{i}(i=1, \ldots, M)$ has the form $\left[g_{k}\left(x_{i}\right), f_{k}\left(x_{i}\right)\right]$, where $k$ is the number of the expert $(k=1, \ldots, N)$, and $g_{k}(x) \leq$ $f_{k}(x)$. In the case of $g_{k}(x)=f_{k}(x)$ we have a normal (non-interval) estimate of the variant $x_{i}$. The problem is to construct a final ranking of options from the set $A$ [7]. The coefficients of the interval estimating method can be obtained only by special procedures that relate to a group of methods of rank transformation, namely: approximation of ranks of a monotonic function [4, 22].

In the Coombs "ordered metrics" method first ranks the criteria, and then the differences between their usefulness. The highest ordered ranking ranks all differences. These differences are then assigned numbers on a scale $[0,1]$ and the weights of the criteria are determined. The disadvantage of this method is that it is difficult to apply with a large number of criteria. For example, for 7 criteria it is necessary to order 21 differences $(0.5 n(n-1))$, and then assign them numbers from 0 to 1 [21].

The evaluation methods on the scale of relations include methods: the method of limit and nominal values, the method of equivalent relations, the midpoint method.

The basis of the interval estimation method is the condition that the importance of the property is characterized by the degree of approximation of the nominal (average) value of the quality indicator to its limit value. Among all the properties of alternatives, the most important ones that determine the properties are always sought to be brought closer to the limit value. Therefore, based on statistical processing of quality indicators of existing alternatives, one value can be obtained by the value of the weight $M_{i}$ of individual indicators. When processing a large enough number of values, the approximate value of $M_{i}$ is calculated as the arithmetic mean [23]. 
The method of equivalent relations. The problem can be formulated as follows: let there be a set $X=\left\{x_{1}, x_{2}, \ldots, x_{n}\right\}$ of alternatives, from the elements of which all decision-makers must arrange in descending order their advantages, from which the $m$-element set $S=\left\{S_{1}, S_{2}, \ldots, S_{m}\right\}$ of rankings is formed. It is necessary to build a relation of expert superiority, ie the relation should express the opinion of the entire expert team, be a compromise [4].

The midpoint method is a variant of the half-division method. Consecutive reductions in the uncertainty interval are made based on the estimate of the derivative function, which is minimized in the middle of the current interval. First, we set the initial interval of localization of the minimum $\left[a_{1}, b_{1}\right]$, at the ends of which the derivative has different signs, set $k=1$ and move on to the main stage. Take the test point $x_{k}$ in the middle of the current interval and check the end criterion $x_{k}=\frac{a_{k}+b_{k}}{2}$. If $\left|f\left(x_{k}\right)\right| \leq \delta$ and $L_{k}=\left|b_{k}-a_{k}\right| \leq \delta$, it is necessary to stop ( $x_{k}=x^{*}$ is the approximating minimum). Reduce the current interval: if $f\left(x_{k}\right)>0$, then $a_{k+1}=a_{k}$ and $b_{k+1}=x_{k}$, and otherwise $-a_{k+1}=x_{k}$ and $b_{k+1}=b_{k}$, Then replace $k$ with $k+$ 1 and return to step 1 [24].

\subsection{Methods of constructing a generalized criterion.}

The group of methods of constructing a generalized criterion includes: methods of approximating the utility function (convolution methods) and methods of transforming preference frequencies (Thurston's method, ATS frequency preference method).

Additive convolution methods can be used when the utility function is presented in additive form [25]: $U\left(f_{1}(x), \ldots, f_{n}(x)\right)=\sum_{i=1}^{n} \lambda_{i} U_{i}\left(f_{i}\left(x_{i}\right)\right)$.

The max (min) convolution method is used when individual criteria (goals) are compared logically. The complex criterion thus looks like this [25]:

$$
\bar{F}=\max \left[\lambda_{i} f_{i}\left(x_{i}\right)\right] \text { або } \underline{F}=\min \left[\frac{f_{i}\left(x_{i}\right)}{\lambda_{i}}\right] \text {. }
$$

Multiplicative convolution methods exist when the criteria are mutually independent in terms of usefulness $[4,25]$ :

$U\left(f_{1}(x), \ldots, f_{n}(x)\right)=\frac{1}{k}\left\{\prod_{i=1}^{n}\left[1+k \lambda_{i} U_{i}\left(f_{i}(x)\right)\right]-1\right\}$, where $k=$ const.

Thurston's method can be represented by the following algorithm [7]: firstly, it constructed a table that characterizes the number of cases when criterion $x_{i}$ is defined as more important than criterion $x_{j}$ (matrix $A$ ). It constructed a table $P$ to identify the percentage of the number of cases when the criterion $x_{i}$ is more significant than $x_{s}$ (matrix $P=\left\|p_{i j}\right\|$, where $p_{i j}=\frac{a_{i j}}{c}$, where $c$ is the number of experts. The matrix $Z$ is used to convert the elements of the matrix $P$ into standard gauges. The calculated $Z_{i}$ is converted by applying the normal distribution table to the percentage of the normal distribution area. The values of $G(z)$ are normalized and taken as coefficients of importance [4].

The experts frequencys preference method can be implemented by the following algorithm [4]. A single ordinal scale is developed for all criteria so that the minimum number for each criterion corresponds to the origin $X=X_{1}, X_{2}, \ldots, X_{n}$. Expert compares all objects lying in each coordinate plane $X_{i}, X_{j}$, where the arrows are placed from a more important object to a less important one. The number of arrows 
(this number characterizes the importance of criterion $X_{i}$ in relation to criterion $X_{j}$ ) directed from criterion $X_{i}$ to criterion $X_{j}$ is calculated. The total number of arrows and will be the number of cases in which criterion $X_{i}$ is more important than criterion $X_{j}$, ie an element of the matrix $A$ of the Thurston's method. The matrix $P$ is constructed for cases when criterion $X_{i}$ is more important than criterion $X_{j}$. Then the formalism of Thurston's method is used.

This method is effective even with a small number of criteria $(2,3)$, when the Churchman-Ackoff methods and Thurston's method do not work $[4,17]$.

\section{Conclusion}

The analysis of the methods showed that there are those that require a large, and even a very large amount of time to communicate with experts, and those that rely more on analytical calculations. For example, the linear convolution method requires more time to communicate with experts than Thurston's method, because it must compare not only the criteria but also their priorities ("criteria weights"). And Thurston's method, in turn, evaluates expertly only cases when one criterion is determined to be more important than another, and then on the basis of the obtained table mathematical operations are performed. The same can be said about the Churchman-Ackoff method and the ranking method, they are also opposite according to the time spent with experts. Of course, such methods can provide greater expert consistency, but it will still be a more subjective decision. In one case, working in a team can benefit the chosen solution, ie the only optimal solution will appear during the discussion. At the same time, otherwise, the collective decision may in some way influence the decision of one or more experts and they may change their decision, although it could be more optimal under the existing conditions. If, for example, we consider the Delphi method, which, by the way, may take too much time, it excludes the opinion of a minority of experts, and pays more attention to the opinion of the majority of experts. However, again, the opinion of one expert on the decision may be more optimal than the opinion of many others. To develop a software system to support decision-making, it is recommended to use the following methods of determining the experts' preferences: methods of analysis the matrices of pairwise comparisons, criteria ranking methods, ordinal scaling methods, evaluation methods on the scale of relations, experts frequency preference methods.

\section{REFERENCES}

1. BOIKO Y., ZIUBINA R., VESELSKA O.: Analiza metod i systemów wspomagających podejmowanie decyzji dla zadań związanych $\mathrm{z}$ bezpieczeństwem cybernetycznym. Przetwarzanie, transformisja I bezpeczenstwo informacji: monografia, Poland, Bielsko-Biala, 2019. P.59-65.

2. BOIKO Y., ZIUBINA R. Classification of decision support systems. Proc. II Inter. scientific-practical Conf. Applied systems and technologies in the information society, October 1, Kyiv 2018, 29-32.

3. BOIKO Y. et al.: Criteria for evaluating the effectiveness of the decision support system. Advances in Intelligent Systems and Computing, (2019), 754, 320-330. 
4. MALAKOV I.: Klasyfikacja metod określania priorytetu kryteriów przy wyborze optymalnego wariantu niskokosztowych systemów automatyki. Notatki naukowe NTS w inżynierii mechanicznej, (2008), 3 (106), 29-40.

5. ANOKHIN A., GLOTOV V., PAVELIEV V., CHERKASHIN A.: Methods for determining the coefficients of the importance of criteria. Automation and telemechanics, (1997), 8, 3-35.

6. LINSTONE, H. A., TUROFF, M.: The delphi method Reading, MA: AddisonWesley. (1975), 3-12.

7. DAVID G. Pairwise Comparison Method. Moscow: Statistics, (1978), 144.

8. PODINOVSKIY V.: Multicriteria problems ordered by importance, homogeneous criteria, AiT. (1976), 11, 118-127.

9. LIN Qizhi, WANG Qin.: Product method of analytic hierarchy process, Asia, Pac J. Oper. Res. (1991) V. 8. $\mathrm{N}^{\circ} 2 ., 135-145$.

10. MARRIOTT, F.: Practical problems in a method of cluster analysis. Biometrics (1971), 501-514.

11. WEI T. H.: The algebraic foundations of ranking theory. Theses. Cambridge: 1952.

12. SAATY, T. L.: Decision making with dependence and feedback: The analytic network process (1996), Vol. 4922, No. 2. Pittsburgh: RWS publications.

13. YUSHMANOV, S.: V. A method for finding weights that does not require a complete matrix of pairwise comparisons. Automation and telemechanics, (1990). 2, 186-189.

14. WAKKER, P., \& DENEFFE, D.: Eliciting von Neumann-Morgenstern utilities when probabilities are distorted or unknown. Management science, (1996) 42 (8), 1131-1150.

15. WILCOXON, F. Individual comparisons by ranking methods. In Breakthroughs in statistics. Springer, New York, NY. (1992). 196-202.

16. SILL, Joseph:. Monotonic networks. (1998). 661-667.

17. JACKSON, MICHAEL C.: The nature of soft systems thinking: The work of Churchman, Ackoff and Checkland. Journal of applied systems analysis, (1982), 17-29.

18. PODINOVSKY, V., Podinovskaya O.: On the incorrectness of the method for analyzing hierarchies. Management Problems (2011) 1.

19. TROFIMOV, V.V., \& TROFIMOVA, L.A.: Management decision making methods. (2013), 335.

20. COOK Wade D. Kress Moshe. A multiple criterion decision mode with ordinal preference data. Eur. J. Oper. Res. (1991). 54. №2, 191-198.

21. COOMBS C.: Psychological Scaling Without a Unit of Measurement Psychological Review. (1990), V. 57, 145-158.

22. MEEKER, W.Q., HAHN, G.J. and ESCOBAR, L.A.: Statistical Intervals: A Guide for Practitioners and Researchers John Wiley \& Sons (2017), 2nd Edition.

23. DALY, Leslie E:. Confidence limits made easy: interval estimation using a substitution method. American Journal of Epidemiology 147.8 (1998), 783-790.

24. HAMMER, Preston C.: The midpoint method of numerical integration." Mathematics Magazine 31.4 (1958), 193-195.

25. LENCZEWSKI, Romuald. Decompositions of the free additive convolution. Journal of Functional Analysis 246.2 (2007), 330-365. 